\title{
Effect of vitamin $E$ in non-alcoholic fatty liver disease: a systematic review and meta-analysis of randomised controlled trials
}

\author{
Iram Amanullah, ${ }^{1}$ Yusra Habib Khan 이 , ${ }^{1}$ Iqraa Anwar, ${ }^{1}$ Aqsa Gulzar, ${ }_{1}^{1}$ \\ Tauqeer Hussain Mallhi, ${ }^{2}$ Ahsan Aftab Raja ${ }^{3}$
}

${ }^{1}$ Institute of Pharmacy, Lahore College for Women University, Lahore, Pakistan

${ }^{2}$ Department of Pharmacy

Practice, Faculty of Pharmaceutical Sciences Government College University, Faisalabad, Pakistan

${ }^{3}$ School of Pharmacy, Taylor's University, Subang Jaya, Selangor, Malaysia

\section{Correspondence to}

Dr Yusra Habib Khan, Institute of Pharmacy, Lahore College for Women University, Jail Road, 54000 Lahore, Punjab, Pakistan; yusrahabib@ymail.com and Dr Tauqeer Hussain Mallhi, Department of Pharmacy Practice, Faculty of Pharmaceutical Sciences, Government College University Faisalabad, Allama Iqbal Road 38000 Faisalabad, Pakistan; tauqeer.hussain.mallhi@ hotmail.com

Received 22 December 2018 Revised 30 May 2019

Accepted 10 July 2019 Published Online First 21 August 2019

Check for updates

(C) Author(s) (or their employer(s)) 2019. No commercial re-use. See rights and permissions. Published by BMJ.

To cite: Amanullah I, Khan

YH, Anwar I, et al.

Postgrad Med J

2019:95:601-611.

\section{ABSTRACT}

The efficacy of vitamin $E$ among patients with nonalcoholic fatty liver disease (NAFLD) is unclear. The current qualitative and quantitative analyses aimed to ascertain the efficacy of vitamin $E$ on clinical outcomes of patients with NAFLD. A systematic search of randomised controlled trials (RCTs) was performed using databases (PubMed, ProQuest, Scopus, EBSCOhost and Ovid) from inception to July 2018. Trials meeting the inclusion criteria were subjected to quality assessment using the Jadad Scoring. All trials meeting the prerequisites information for meta-analysis were subjected to quantitative synthesis of results. Nine RCTs (five in adults and four in children) were included. Four of the five RCTs on adults demonstrated significant improvements in alanine transaminase and other liver function surrogates in patients with NAFLD. On the other hand, only one of the four RCTs conducted on children showed significant improvements in liver functions with the use of vitamin E. Although quantitative synthesis of available data revealed insignificant differences between vitamin $\mathrm{E}$ and placebo, still the use of vitamin E improves the level of alanine transaminase and aspartate transaminase by -1.96 and -0.59 , with heterogeneity of $\mathrm{I}^{2}=67 \%$ and $\mathrm{I}^{2}=0 \%$, respectively. Adjuvant vitamin $\mathrm{E}$ therapy provides significant biochemical and histological improvements in adult patients with NAFLD, while paediatric patients showed insignificant efficacy compared with placebo. Lifestyle interventions along with vitamin $\mathrm{E}$ can provide much better results. Data, including the impact of vitamin E on hepatic histology, are still lacking. Moreover, the short duration of trials limits the conclusion on the safety and efficacy of proposed treatments.

\section{INTRODUCTION}

Non-alcoholic fatty liver disease (NAFLD) is characterised by lipid deposition in the liver parenchyma without significant history of alcohol consumption or other secondary causes. ${ }^{1}$ Secondary causes may include hepatitis, certain medications and endocrine conditions. ${ }^{2}$ NAFLD develops in four stages, comprising simple hepatic steatosis and non-alcoholic steatohepatitis (NASH), leading to fibrosis and cirrhosis. ${ }^{3}$ It has been estimated that approximately one billion individuals worldwide are affected by NAFLD. ${ }^{4}$ NAFLD is considered the most prevalent liver disease, with an estimated prevalence of around 20\%-30\% in the Western population. ${ }^{1}$
NAFLD is mainly associated with obesity, insulin resistance, hypertension and dyslipidaemia. ${ }^{5}$ Insulin resistance and oxidative stress play a vital role in the progression towards NAFLD in all age groups. ${ }^{6}$ Oxidative stress occurs as a result of several mechanisms mediated by reactive oxygen species (ROS) in the liver. ROS reacts with the cells, leading to impaired nucleotide and protein synthesis, and is also responsible for inducing apoptosis and cell death, and interferes with the repair mechanisms. These mechanisms in turn may change the physical state of the plasma membrane and cause functional impairments. ${ }^{7}$

Vitamin E limits membrane injury precipitated by ROS and is considered a promising antioxidant entity for the treatment of NAFLD. ${ }^{7}$ Other physiological treatments for NAFLD include lifestyle interventions and physical exercise, along with antioxidant therapy. ${ }^{8}$ Various investigations have been conducted to evaluate the effectiveness of antioxidants for NAFLD. ${ }^{9}$ Literature suggests a promising role of vitamin $\mathrm{E}$, along with lifestyle modifications, for the treatment of NAFLD. However, existing studies are accompanied by several limitations, which precludes drawing firm conclusions with regard to the efficacy of vitamin E on various clinical outcomes in patients with NAFLD. ${ }^{10}$

Despite numerous trials conducted to assess the efficacy of vitamin $\mathrm{E}$ in patients with NAFLD, there is a dearth of systematic review and meta-analysis drawing firm conclusions from these studies. Sato et $a l^{10}$ in 2015 performed a pool analysis to evaluate the benefits of vitamin E in NAFLD. However, their analysis is limited by several shortcomings. First, the authors have selected only five randomised controlled trials (RCTs) and excluded other trials due to stringent exclusion criteria. Second, their review does not provide qualitative synthesis of all available RCTs. In this context, qualitative and quantitative syntheses of all available trials were performed to quantify the magnitude of treatment response associated with vitamin $\mathrm{E}$ in improving alanine transaminase (ALT), aspartate transaminase (AST), body mass index (BMI), steatosis, inflammation, ballooning, fibrosis and histology in patients with NAFLD of all age groups.

\section{MATERIALS AND METHODS Information sources}

Studies were searched by three independent reviewers (IAm, IAn, AG) using electronic databases. 


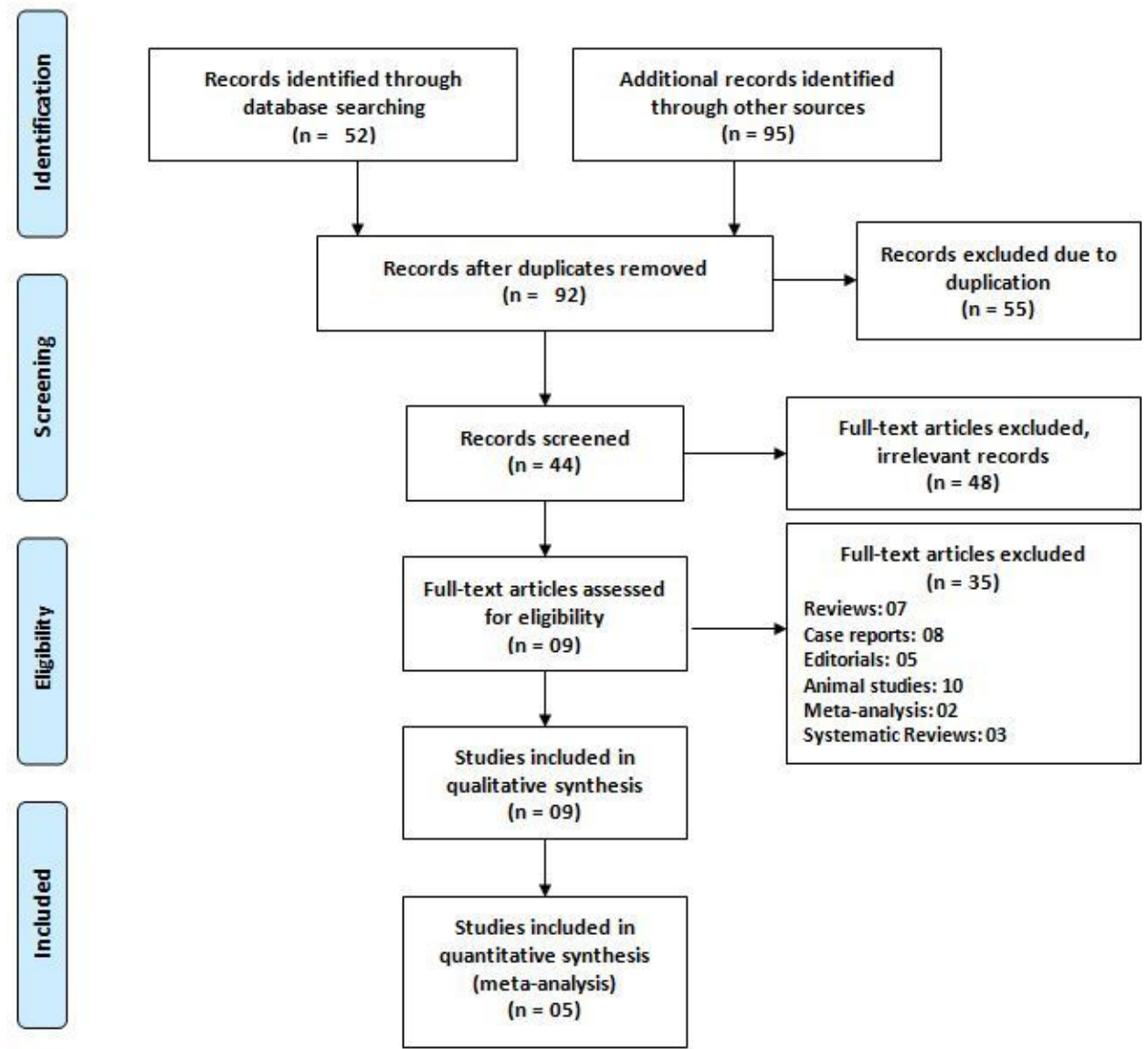

Figure 1 Flow chart of study selection (Preferred Reporting Items for Systematic Reviews and Meta-Analyses diagram).

Our search applied to PubMed, ProQuest, Scopus, EBSCOhost, Ovid, Journal of American Medical Association (JAMA), ScienceDirect, EMBASE, American Journal of Gastroenterology, Clinical Trial Directories, MEDLINE and Google Scholar from date of database inception to July 2018. The PubMed search strategy served as a reference for the development of search strategies for the remaining databases. The search terms used were "vitamin E", "nonalcoholic fatty liver disease", "nonalcoholic steotohepatitis", "clinical outcomes", "liver function tests" and "antioxidants". The search included only published RCTs and was limited to human studies of all genders and age groups.

\section{Inclusion criteria}

The inclusion criteria were clinical trials evaluating the effectiveness of vitamin $\mathrm{E}$ in patients with NAFLD, regardless of age and gender, by comparing with controls. Trials investigating the impact of vitamin $\mathrm{E}$ on at least one treatment outcome (ALT, AST, BMI, steatosis, inflammation, ballooning, fibrosis and histological improvements) were considered for inclusion.

\section{Exclusion criteria}

We excluded studies involving (1) patients who are pregnant and with co-existing liver disease, including alcoholic liver disease, autoimmune hepatitis, hepatitis B and hepatitis C; (2) drugs such as valproate, amiodarone, prednisone and tamoxifen on account of their involvement in the pathogenesis of steatosis; and (3) bariatric surgery, environmental toxins or total parenteral nutrition, which may cause secondary NAFLD. Moreover, all other studies other than RCTs and those with non-extractable data were excluded from the current review.

Table 1 Jadad Scoring for quality assessment of included trials

\begin{tabular}{|c|c|c|c|c|c|c|}
\hline Trials & $\begin{array}{l}\text { Randomisation } \\
\text { mentioned }\end{array}$ & $\begin{array}{l}\text { Concealment of } \\
\text { randomisation }\end{array}$ & Blinding & $\begin{array}{l}\text { Appropriate blinding } \\
\text { method }\end{array}$ & $\begin{array}{l}\text { Reporting of } \\
\text { withdrawals }\end{array}$ & $\begin{array}{l}\text { Jadad } \\
\text { score }\end{array}$ \\
\hline Harrison et al/ ${ }^{12}$ & Yes & Yes & Yes & Yes & Yes & 5 \\
\hline Vajro et a $\left.\right|^{18}$ & Yes & Yes & Yes & Yes & Unclear & 4 \\
\hline Nobili et al ${ }^{17}$ & Yes & Yes & Yes & Yes & Yes & 5 \\
\hline Sanyal et a $\left.\right|^{15}$ & Yes & Unclear & Yes & Yes & Yes & 4 \\
\hline Hoofnagle et al ${ }^{14}$ & Yes & Unclear & Yes & Unclear & Yes & 3 \\
\hline Aller et al ${ }^{1}$ & Yes & Unclear & Yes & Unclear & Unclear & 2 \\
\hline
\end{tabular}




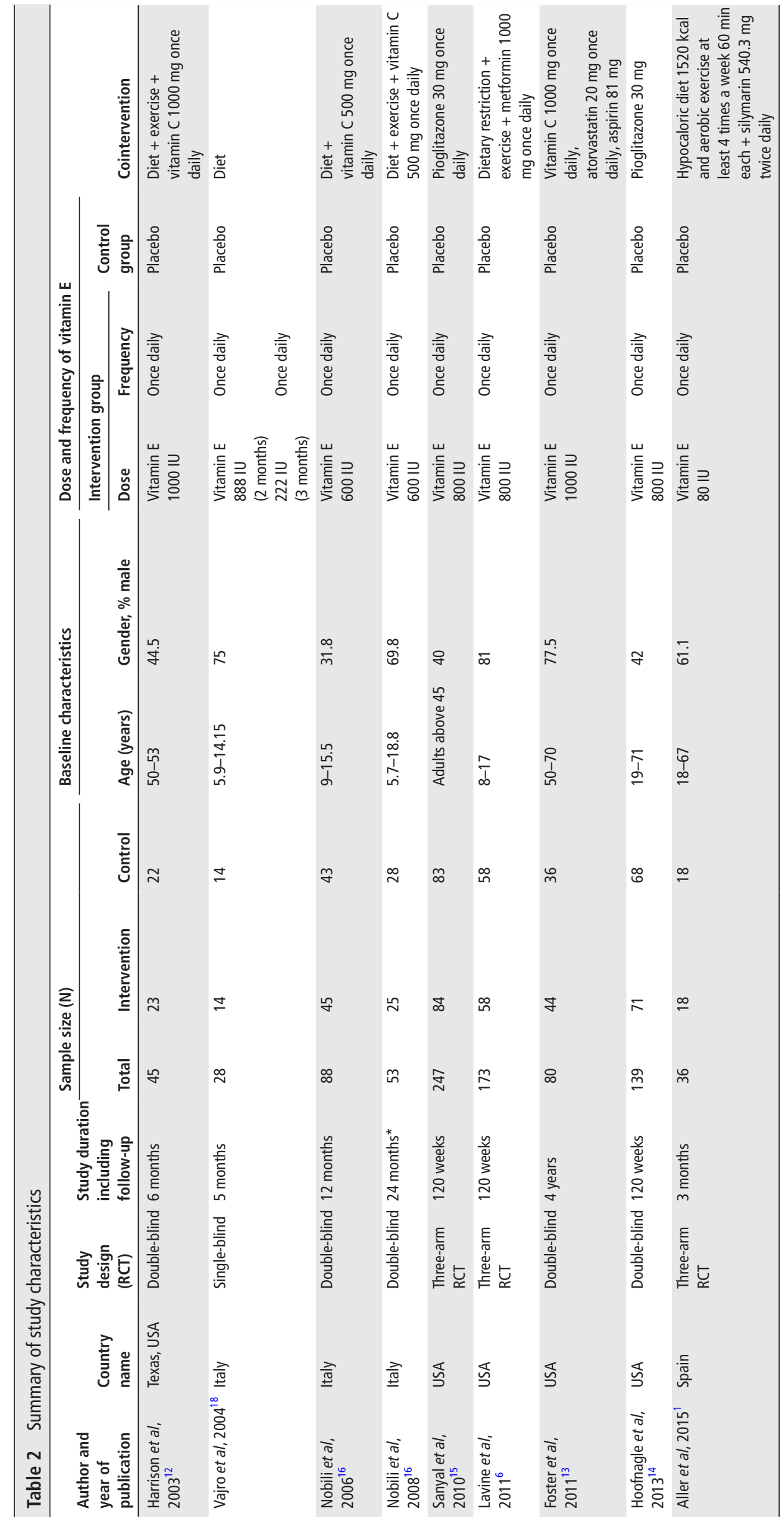




\section{Data extraction}

Three researchers independently screened all titles and abstracts retrieved from the electronic databases using the defined selection criteria. Then, the full text of each potentially eligible article was obtained and screened independently by the researchers to further assess its suitability for inclusion in this review. All the results were collected, compiled and compared. Any conflict or deviation was solved through mutual consultation and concurrence.

\section{Study selection}

A total of 147 studies were initially identified and considered potentially relevant. Of these, 111 studies did not meet the inclusion criteria. Twenty-seven studies were evaluated in detail to determine whether they described the role of vitamin $\mathrm{E}$ in NAFLD. Subject to further exclusion as described in figure 1, nine RCTs meeting the selection criteria were considered for the current review and analysis. Figure 1 illustrates the Preferred Reporting Items for Systematic Reviews and Meta-Analyses diagram of study selection.

\section{Quality assessment}

Evaluation and scoring for RCTs were based on the Jadad Scoring System. ${ }^{11}$ The Jadad scale, sometimes known as Jadad scoring or the Oxford Quality Scoring System, is a procedure used to independently assess the methodological quality of clinical trials. The JSC scores studies from 0 to 5 , where a high score indicates good-quality study. The components of JSC include randomisation ( 2 points), blinding ( 2 points) and account of all patients ( 1 point). The overall Jadad score for each included RCT is described in table 1 .

\section{Quantitative synthesis}

For absolute values of ALT, ALT, BMI, steatosis, lobular inflammation, hepatocellular ballooning, fibrosis and histological improvement at last visit on treatment, we estimated the pooled mean differences between the two treatment groups (vitamin $\mathrm{E}$ and control) and the 95\% CI. Only studies having the required mean values were included for pool analysis. All statistical analyses were done using the Review Manager V.5.2 (The Nordic Cochrane Centre, The Cochrane Collaboration, Copenhagen, Denmark). The $\mathrm{I}^{2}$ statistic was used to assess heterogeneity. A fixed-effect model was used when $\mathrm{I}^{2}$ was $<50 \%$, which indicated heterogeneity. If $\mathrm{I}^{2}$ was $>50 \%$, a random-effects model was used after consideration of the potential sources of heterogeneity.

\section{RESULTS}

A total of nine RCTs published in 2003-2015 were included in the current review. Of these, five trials were from the USA, three from Italy and only one trial was conducted in Spain. A summary of the characteristics of the included trials is described in table 2 .

\section{Descriptive summary of included trials}

All trials included 889 patients with the mean age ranging from $9.88 \pm 3.97$ to $59.40 \pm 6.0$ years. Five trials included adult patients as the study population, ${ }^{12-15}$ while the remaining four studies included children. ${ }^{6}{ }^{16-18}$ The study duration of trials varied from 6 months to 4 years, including the follow-up period. Table 2 demonstrates the variability of the included trials.

\section{Description of intervention}

Vitamin E was the intervention in all RCTs and compared with at least on control group. There was a single-blind RCT

Table 3 Summary of reported outcomes in RCTs conducted on adults and children

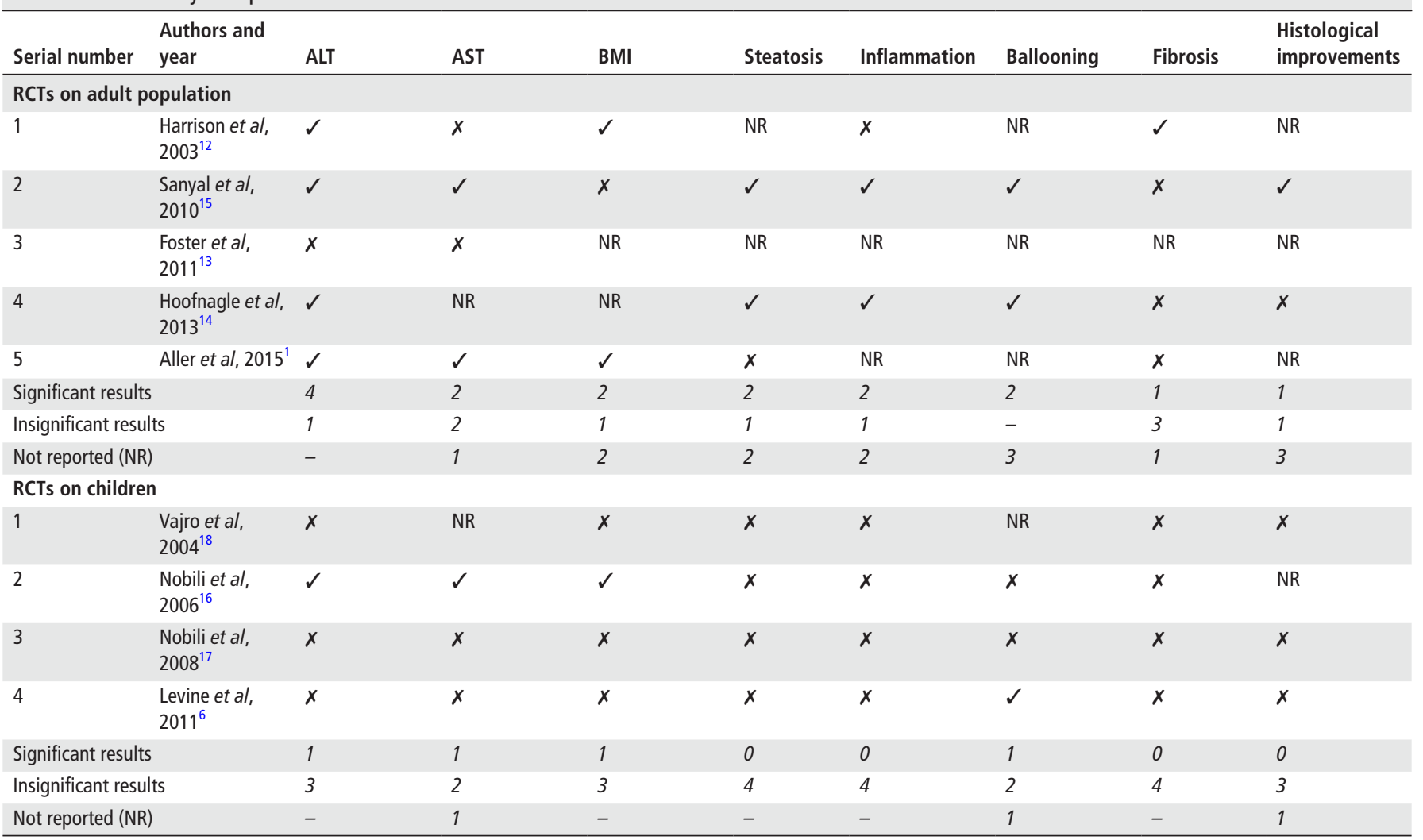


Table 4 Impact of vitamin E on ALT, AST, BMI and steatosis score in trials

\begin{tabular}{|c|c|c|c|c|c|c|c|c|c|c|c|c|}
\hline \multirow{3}{*}{$\begin{array}{l}\text { Author and } \\
\text { year }\end{array}$} & \multicolumn{12}{|c|}{ Outcomes with respect to control and intervention group } \\
\hline & \multicolumn{3}{|l|}{ ALT (U/L) } & \multicolumn{3}{|l|}{ AST (U/L) } & \multicolumn{3}{|l|}{ BMI $\left(\mathrm{kg} / \mathrm{m}^{2}\right)$} & \multicolumn{3}{|c|}{ Steatosis score } \\
\hline & Intervention & Control & $P$ value & Intervention & Control & $P$ value & Intervention & Control & $P$ value & Intervention & Control & $P$ value \\
\hline $\begin{array}{l}\text { Harrison et al, } \\
2003^{12}\end{array}$ & -12.3 & -31 & 0.007 & * & * & NR & -1.1 & -1.6 & 0.012 & NR & NR & NR \\
\hline $\begin{array}{l}\text { Vajro et al, } \\
2004^{18}\end{array}$ & $\begin{array}{l}-31.90 \dagger \\
-24.09 \ddagger\end{array}$ & $\begin{array}{l}-26.36 \dagger \\
-29.9 \\
2 \ddagger\end{array}$ & $\begin{array}{l}0.54 \dagger \\
0.6 \\
6 \ddagger\end{array}$ & NR & NR & NR & NR & NR & NR & * & * & NR \\
\hline $\begin{array}{l}\text { Nobili et al, } \\
2006^{16}\end{array}$ & -36.35 & -24.44 & 0.0001 & -13.95 & -10.05 & 0.001 & -2.39 & -1.83 & 0.0001 & $\S$ & $\S$ & NR \\
\hline $\begin{array}{l}\text { Nobili et al, } \\
2008^{17}\end{array}$ & -31 & -29 & 0.6 & -12 & -15 & 0.6 & -3.7 & -3.1 & 0.4 & -1 & 0 & 0.07 \\
\hline $\begin{array}{l}\text { Sanyal et al, } \\
2010^{15}\end{array}$ & -37 & -20.1 & 0.001 & -21.3 & -3.8 & $<0.001$ & 0.1 & 0.4 & 0.50 & -1.026 & -0.589 & 0.005 \\
\hline $\begin{array}{l}\text { Lavine et al, } \\
2011^{6}\end{array}$ & -48.3 & -35.2 & 0.07 & -22.8 & -20.4 & 0.32 & -0.03 & -0.01 & 0.78 & -0.621 & -0.399 & 0.18 \\
\hline $\begin{array}{l}\text { Foster et al, } \\
2011^{13}\end{array}$ & * & NR & NR & * & NR & NR & NR & NR & NR & $\begin{array}{l}\text { Decreased } \\
\text { based on } \\
\text { abdominal CT } \\
\text { scan }\end{array}$ & NR & NR \\
\hline $\begin{array}{l}\text { Hoofnagle et } \\
a l, 2013^{14}\end{array}$ & -21.6 & -5.1 & NR & NR & NR & NR & NR & ๆ & NR & -0.7 & -0.7 & $\begin{array}{l}\text { Vitamin } \\
E=<0.001 \\
\text { Placebo }=<0.001\end{array}$ \\
\hline $\begin{array}{l}\text { Aller et al, } \\
2015^{1}\end{array}$ & -3.7 & -16.1 & $<0.05$ & -1 & -5.6 & $<0.05$ & -5.1 & -2.9 & $<0.05$ & * & * & NR \\
\hline
\end{tabular}

(-) Improvement in the outcome (mean response value - mean baseline value).

*Non-significant.

tEvaluation at month 2; this $\mathrm{p}$ value indicates difference between control and intervention group.

\#Evaluation at month 5; this $p$ value indicates difference between control and intervention group.

$\S$ Steatosis was present in all biopsies, mostly macrovesicular, but frequently associated with microvesicular steatosis.

ПSignificant improvement.

ALT, alanine transaminase; AST, aspartate transaminase; BMI, body mass index; NR, not reported.

comparing vitamin E with placebo. ${ }^{14}$ Two studies had three-arm design, one comparing vitamin $\mathrm{E}$ with metformin and placebo, ${ }^{6}$ and the other compared vitamin E with silymarin and placebo. ${ }^{1}$ Moreover, all remaining six RCTs were double-blind, in which vitamin E was compared with placebo. ${ }^{11} 1215-18$

It is important to note that all trials have variations in dose (international unit), duration and frequency of vitamin $\mathrm{E}$ (table 2). To enhance the efficacy of vitamin E, cointerventions including other medications or lifestyle modifications were suggested along with vitamin $\mathrm{E}$. Three studies ${ }^{16-18}$ used vitamin $\mathrm{C}$ along with vitamin $\mathrm{E}$, while one study ${ }^{14}$ used vitamin E and pioglitazone (table 2).

\section{Description of cointervention}

Diet and exercise were cointerventions in four trials. ${ }^{161218}$ In two trials, diet was the only cointervention, applied on both the intervention and the control group. ${ }^{11} 14$ Three trials included only vitamin E and control group, without any cointervention. ${ }^{131617}$ The cointerventions are described in table 2 .

\section{Effect of vitamin E on outcomes}

In adult patients with NAFLD, adjuvant vitamin $E$ therapy significantly improved the biochemical and histological parameters of the liver. Four out of five trials among adults showed significant improvements in ALT. ${ }^{1} 131718$ These trials also demonstrated significant improvements in other outcomes.

Among trials conducted on children, Nobili et al ${ }^{16}$ showed improvements in ALT, AST and BMI, and Lavine et $a l^{6}$ demonstrated improved ballooning scores with the use of adjuvant vitamin $\mathrm{E}$ therapy. However, other outcomes were not improved in these four trials conducted on children (table 3 ).
It must be noted that the level of significance varies in some trials. Sanyal et $a l^{15}$ considered $\mathrm{p}<0.025$ as significant and Lavine et $a l^{6}$ made significance at $\mathrm{p}<0.01$, while all other trials estimated significance at $\mathrm{p}<0.05$.

\section{Effect of adjuvant vitamin E on ALT}

The effect of adjuvant vitamin E on ALT was demonstrated in all RCTs included in the review (table 4).

\section{RCTs conducted on adults}

The effect of adjuvant vitamin E on ALT was demonstrated in all five trials on adult population. Hoofnagle et $a l^{14}$ showed more significant drop in ALT values in the intervention group (IG) compared with the control group (CG). In contrast, Harrison et $a l^{12}$ showed more significant drop in ALT values in CG than in IG. Sanyal et $a l^{15}$ and Aller $e t a l^{1}$ showed a significant drop in ALT values in both IG and CG, but the drop was much prominent in IG. Foster et $_{\mathrm{al}}{ }^{13}$ showed insignificant improvements in ALT levels.

\section{RCTs conducted on children}

The effect of adjuvant vitamin E on ALT was demonstrated in all four trials conducted on children. Nobili et al ${ }^{16}$ showed more significant drop in ALT values in IG compared with CG. Lavine et $a l,{ }^{6}$ Nobili et $a l^{17}$ and Vajro et al ${ }^{18}$ showed insignificant improvements in ALT levels.

\section{Effect of adjuvant vitamin E on AST}

The effect of adjuvant vitamin E on AST was demonstrated in seven trials (table 4). 
RCTs conducted on adults

The effect of adjuvant vitamin E on AST was demonstrated in four out of five trials on adult population. Sanyal et $a l^{15}$ revealed more significant drop in AST values in IG compared with CG. Aller $e t a l^{1}$ showed mild drop in IG compared with CG, while Harrison $e t a l^{12}$ and Foster $e t a l^{13}$ showed insignificant improvements.

\section{RCTs conducted on children}

The effect of adjuvant vitamin E on AST was demonstrated in three out of four trials. Nobili et $_{\mathrm{al}} \mathrm{l}^{16}$ indicated more significant drop in AST in IG compared with CG. However, Lavine et $a l^{6}$ and Nobili et $a l^{17}$ showed insignificant improvements in AST with the use of vitamin $\mathrm{E}$.

\section{Effect of adjuvant vitamin E on BMI}

The effect of adjuvant vitamin E on BMI was demonstrated in seven trials (table 4).

\section{RCTs conducted on adults}

The effect of adjuvant vitamin E on BMI was demonstrated in three out of five trials. Aller $e t a l^{1}$ showed a significant improvement in BMI in IG compared with CG. Harrison et al ${ }^{12}$ showed a significant improvement in BMI in CG compared with IG. On the other hand, Sanyal et $a l^{15}$ showed insignificant improvement in IG compared with CG.

\section{RCTs conducted on children}

The effect of adjuvant vitamin E on BMI was demonstrated in all four trials conducted on children. Nobili et al $^{16}$ showed a significant improvement in BMI in IG compared with CG. In contrast, Vajro et $a l,{ }^{18}$ Nobili et $a l^{17}$ and Lavine et $a l^{6}$ showed insignificant improvements in BMI in both IG and CG.

\section{Effect of adjuvant vitamin $E$ on steatosis score}

The effect of adjuvant vitamin $\mathrm{E}$ on steatosis was demonstrated in seven trials (table 4).

\section{RCTs conducted on adults}

The effect of adjuvant vitamin $\mathrm{E}$ on steatosis was demonstrated in three trials. Sanyal et $a l^{15}$ and Hoofnagle et $a l^{14}$ showed significant drop in steatosis score in IG compared with CG, while Aller $e t a l^{1}$ showed an almost equal drop in steatosis score in both IG and CG.

\section{RCTs conducted on children}

The effect of adjuvant vitamin $\mathrm{E}$ on steatosis was demonstrated in all four trials on children. All RCTs demonstrated ${ }^{616-18}$ insignificant improvements of steatosis score in IG compared with CG.

\section{Effect of adjuvant vitamin $E$ on inflammation score}

The effect of adjuvant vitamin $\mathrm{E}$ on inflammation was demonstrated in seven trials (table 5).

\section{RCTs conducted on adults}

The effect of adjuvant vitamin $\mathrm{E}$ on inflammation score was demonstrated in three trials. Sanyal et $a l^{15}$ and Hoofnagle et $a l^{14}$ showed more drop in inflammation score in IG compared with CG. However, Harrison et $a l^{12}$ showed insignificant improvements. 


\section{RCTs conducted on children}

The effect of adjuvant vitamin E on inflammation was demonstrated in all four trials. All the trials did not show any significant improvements in IG compared with CG with the use of vitamin E. ${ }^{616-18}$

Effect of adjuvant vitamin $\mathrm{E}$ on ballooning score

The effect of adjuvant vitamin $\mathrm{E}$ on ballooning was demonstrated in five out of nine trials (table 5).

\section{RCTs conducted on adults}

The effect of adjuvant vitamin E on ballooning score was demonstrated in two trials. Sanyal et $a l^{15}$ and Hoofnagle $e t a l^{14}$ showed a minute drop of ballooning score in IG compared with CG.

\section{RCTs conducted on children}

The effect of adjuvant vitamin E on ballooning score was demonstrated in three of four trials conducted on children. Lavine et a $l^{6}$ showed a minute drop of ballooning score in IG compared with CG. On the other hand, Nobili et $a l^{16}$ and Nobili et $a l^{17}$ showed insignificant improvements.

Effect of adjuvant vitamin $\mathrm{E}$ on fibrosis score

The effect of adjuvant vitamin $\mathrm{E}$ on fibrosis was demonstrated in eight trials (table 5).

\section{RCTs conducted on adults}

The effect of adjuvant vitamin $\mathrm{E}$ on fibrosis score was demonstrated in four trials. Harrison et $a l^{12}$ showed significant improvement in fibrosis score in IG compared with CG. Sanyal et $a l,{ }^{15}$ Hoofnagle et $a l^{14}$ and Aller et $a l^{1}$ showed insignificant improvements in fibrosis score in IG compared with CG.

\section{RCTs conducted on children}

The effect of adjuvant vitamin E on inflammation was demonstrated in four trials. All trials showed insignificant improvements in fibrosis score in IG compared with CG. ${ }^{6}$ 16-18

Effect of adjuvant vitamin $\mathrm{E}$ on histological improvements

The effect of adjuvant vitamin $\mathrm{E}$ on histological improvement was demonstrated in five out of nine trials (table 5).

\section{RCTs conducted on adults}

The effect of adjuvant vitamin $\mathrm{E}$ on histological improvement was demonstrated in only two trials. Sanyal et al ${ }^{15}$ showed significant histological improvement in IG compared with CG, while Hoofnagle et $a l^{14}$ showed insignificant improvements.

\section{$R C T$ s conducted on children}

The effect of adjuvant vitamin $\mathrm{E}$ on histological improvement was demonstrated in three trials. All RCTs showed insignificant histological improvements in IG compared with CG. ${ }^{6} 1718$

The quantitative effect of vitamin $\mathrm{E}$ versus placebo on six outcomes is described in figures 2 and 3 . The impact of vitamin E on ALT levels was analysed through five studies that fell in our inclusion criteria. Vitamin E was able to reduce the ALT levels by $-1.96(95 \% \mathrm{CI}-9.24$ to $5.31 ; \mathrm{p}=0.60)$ in comparison with placebo. The level of heterogeneity was moderately high $\left(\mathrm{I}^{2}=67 \%\right)$. Moreover, vitamin $\mathrm{E}$ was able to reduce the AST counts by -11.39 (95\% CI -37.15 to 13.68 ; $p=0.37$ ) when compared with placebo. The level of heterogeneity was high $\left(\mathrm{I}^{2}=99 \%\right)$; thereby, the study of Lavine et $a l^{6}$ was omitted given its effect size in comparison with other studies. Subsequently, the level of heterogeneity was reduced $\left(\mathrm{I}^{2}=0 \%\right)$ along with $95 \% \mathrm{CI}$ $(-0.59(-4.18$ to 3.01$) ; \mathrm{p}=0.75)$ (figure 2$)$.

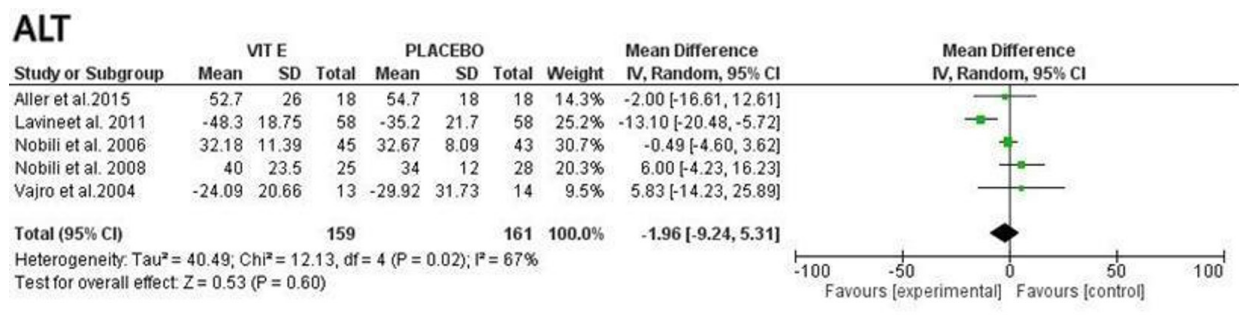

AST

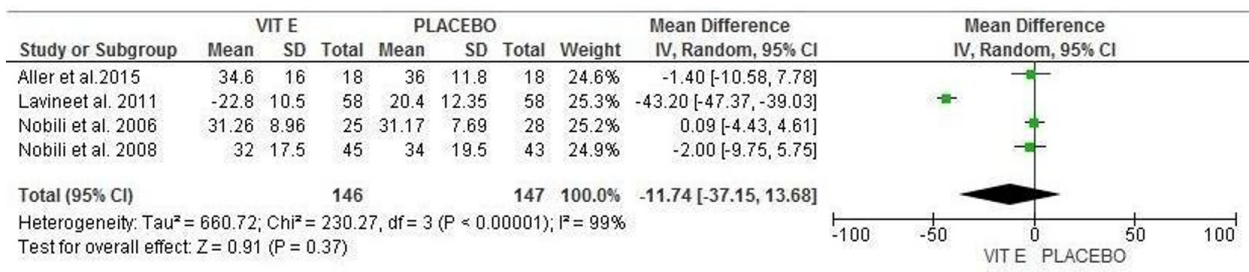

AST by excluding Lavine et al. 2011

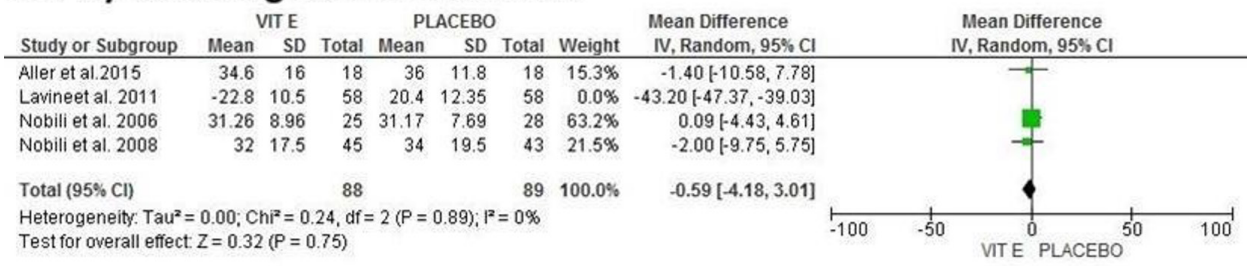

Figure 2 Impact of vitamin E on ALT and AST. ALT, alanine transaminase; AST, aspartate transaminase; VIT E, vitamin E; IV, Inverse Variance. 
Altogether four studies were analysed to observe the impact of vitamin E on BMI. Our results suggest that vitamin E was able to reduce BMI by $-0.07(95 \% \mathrm{CI}-0.74$ to $0.60 ; \mathrm{p}=0.84)$ in comparison with placebo. The level of heterogeneity was low $\left(\mathrm{I}^{2}=31 \%\right)$. Two studies were analysed for the impact of vitamin $\mathrm{E}$ on ballooning, which suggested that vitamin $\mathrm{E}$ did not have any significant impact on ballooning score $(0.69$ (95\% CI -1.86 to $3.23) ; p=0.60)$. The level of heterogeneity was high $\left(I^{2}=99 \%\right)$. Furthermore, vitamin $\mathrm{E}$ was able to reduce the fibrosis score by $-0.52(95 \% \mathrm{CI}-1.40$ to $36 ; \mathrm{p}=0.24)$ with high level of heterogeneity $\left(\mathrm{I}^{2}=94 \%\right)$. Vitamin $\mathrm{E}$ improved histological findings in comparison with placebo by $-0.72(95 \% \mathrm{CI}-1.75$ to 0.3 ; $\mathrm{p}=0.17)$ with moderate level of heterogeneity $\left(\mathrm{I}^{2}=68 \%\right)$ among the studies (figure 3).

\section{DISCUSSION}

NAFLD is closely related to metabolic syndrome. ${ }^{19}$ It can be more acute, and progressive disease may lead to the development of cirrhosis. ${ }^{20}$ Lifestyle modifications, including diet and weight reduction, are the mainstay of management for patients with NAFLD. However, patients hardly achieve their lifestyle goals, and pharmacological treatment is usually considered to achieve optimum outcomes. ${ }^{21}$ Although data on the pathogenesis of NAFLD are scarce, oxidative stress is observed to be a major contributing factor to the evolution and progression of NAFLD among patients. $^{10}$

Vitamin E is considered a chain-breaking antioxidant in free radical reactions such as lipid peroxidation. It forms complexes with the electrons of the free radicals and provides protection against lipid peroxidation. In this context, vitamin $\mathrm{E}$ is considered an effective entity against ROS and protects against cytokine 'transforming growth factor beta 1 (TGF- $\beta 1$ )'-related liver fibrosis. ${ }^{22}$ The association of NAFLD with insulin resistance, obesity and hyperlipidaemia is well documented. Oxidative stress, endotoxin-induced cytokine release and metabolic changes contribute to the progression of the disease. ${ }^{23} \mathrm{Li}$ et $\mathrm{al}^{24}$ in 2015 concluded that vitamin $\mathrm{E}$ improves the integrity of the liver by reducing response to membrane transporter involved in fatty acid uptake.

Numerous observational cohort and case-control studies have been performed to determine the effect of vitamin $\mathrm{E}$ on NAFLD, but the findings are not conclusive. ${ }^{25}$ In 2011 , Erhardt et $a l^{25}$ compared the antioxidant level of patients with NAFLD with the control, and concluded decreased level of tocopherols in NAFLD. Sanyal et $a l^{15}$ revealed that vitamin $\mathrm{E}$ is superior over placebo and significantly improves hepatic inflammation, steatosis and hepatic cellular ballooning in NAFLD, but the improvement in fibrosis was not evident. Similarly Nobili et $a l^{17}$ did not find any significant change
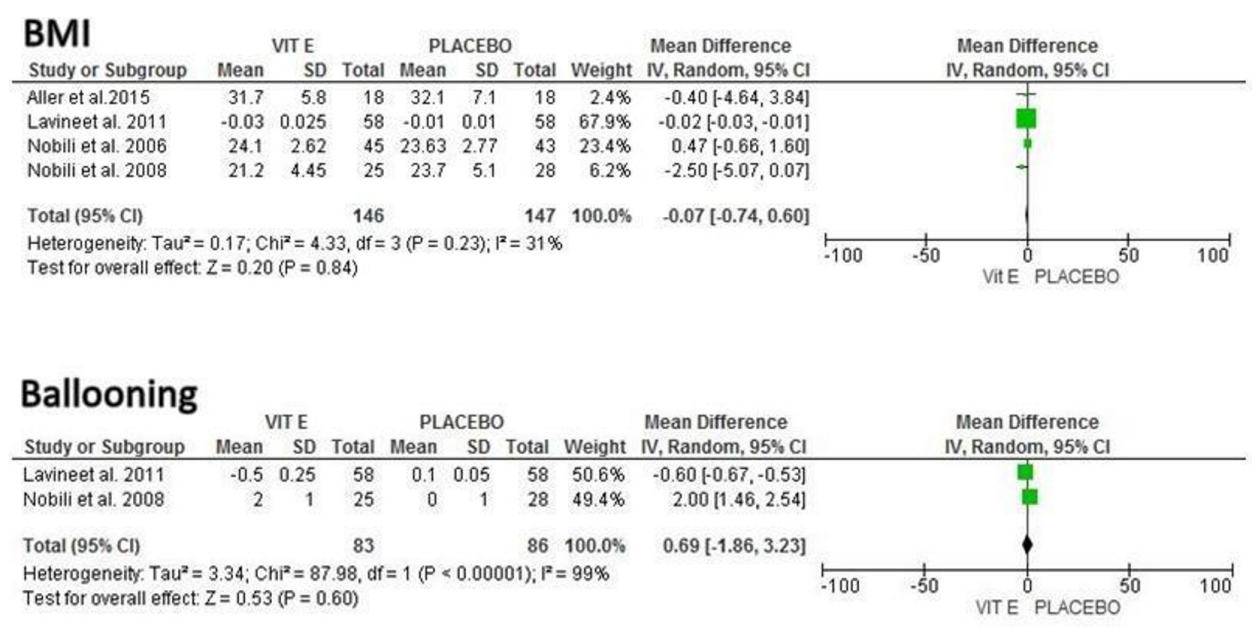

\section{Fibrosis}

\begin{tabular}{|c|c|c|c|c|c|c|c|c|c|c|c|}
\hline \multirow[b]{2}{*}{ Study or Subgroup } & \multicolumn{3}{|c|}{ VIT E } & \multicolumn{3}{|c|}{ PLACEBO } & \multicolumn{3}{|c|}{ Mean Difference } & \multirow{2}{*}{$\begin{array}{l}\text { Mean Difference } \\
\text { IV, Random, } 95 \% \mathrm{Cl}\end{array}$} & \\
\hline & Mean & SD & Total & Mean & SD & Total & Weight & IV, Random, $95 \% \mathrm{Cl}$ & & & \\
\hline Lavineet al. 2011 & -0.3 & 0.3 & 58 & -0.2 & 0.25 & 58 & $52.9 \%$ & $-0.10[-0.20,0.00]$ & & 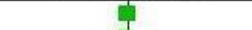 & \\
\hline Nobili et al. 2008 & 1 & 1 & 25 & 2 & 0.5 & 28 & $47.1 \%$ & $-1.00[-1.43,-0.57]$ & & 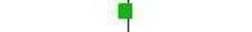 & \\
\hline Total $(95 \% \mathrm{Cl})$ & & & 83 & & & 86 & $100.0 \%$ & $-0.52[-1.40,0.36]$ & & & \\
\hline $\begin{array}{l}\text { Heterogeneity: Tau }{ }^{2}= \\
\text { Test for overall effect }\end{array}$ & $\begin{array}{l}0.38 ; C \\
Z=1.17\end{array}$ & & $\begin{array}{l}15.71, d \\
0.24)\end{array}$ & $\mathrm{df}=1(\mathrm{P}$ & $<0.00$ & $001) ; 1^{2}$ & $=94 \%$ & & -100 & VIT E PLACEBO & 100 \\
\hline
\end{tabular}

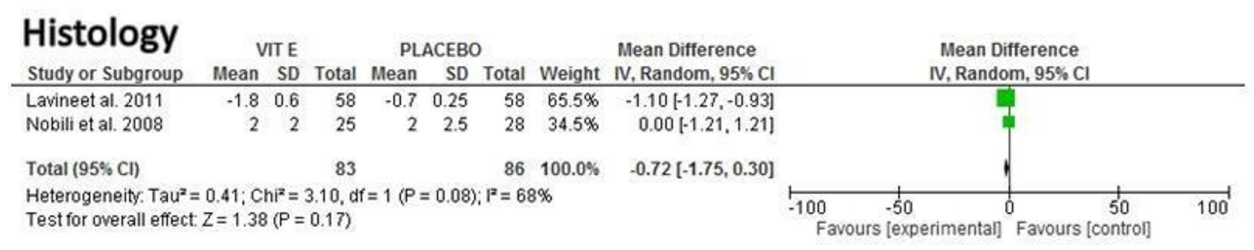

Figure 3 Impact of vitamin E on BMI, ballooning, fibrosis and histology. BMI, body mass index; VIT E, vitamin E; IV, Inverse Variance. 
in fibrosis. ${ }^{17}$ However, the efficacy of vitamin $\mathrm{E}$ for the improvement in fibrosis score and histological responses has been evident in available data. ${ }^{26}$

Vitamin E significantly improves ALT, AST, histological changes, steatosis, inflammation and hepatocellular ballooning. ${ }^{10}$ Aller et $a l^{1}$ found that the combination therapy of vitamin $\mathrm{E}$ and silymarin shows significant improvements in ALT and AST, which might be attributed to the reduction of enzyme dispersion in extracellular medium and restoration of normal membrane permeability of the liver. The impact of vitamin $\mathrm{E}$ has also been evaluated in one meta-analysis which illustrated that vitamin E therapy causes significant improvements in ALT/AST levels. ${ }^{10}$

Hoofnagle et $a l^{14}$ in 2010 concluded that weight loss should be the first priority as obesity can lead to worsening of fibrosis, hence disease progression. One trial showed that vitamin E improved ALT and that histological responses were more evident in patients with NAFLD who lost weight. ${ }^{14}$ In 2017, Zöhrer et $a l^{27}$ illustrated that a combination therapy of docosahexaenoic acid-choline-vitamin $\mathrm{E}$ has shown significant improvements in ALT, steatosis and ballooning among paediatric patients with NASH. It was the first study conducted on children with NASH concluding the efficacy of three nutritional supplements in combination with diet and exercise. ${ }^{27}$

Although the qualitative analysis in the current review describes the promising impact of adjuvant vitamin $\mathrm{E}$ on almost all clinical outcomes of patients with NAFLD, pool analysis revealed that vitamin E therapy provides favourable benefits for ALT and AST only. Meta-analysis showed improvements in BMI, ballooning, fibrosis and histology, but such improvements were not much significant to draw a firm conclusion. These discrepancies in the results of pool analysis might be attributed to several reasons. Most of the studies conducted on adult population do not have values of mean and SD, which are prerequisites to conduct an analysis. Moreover, there were wide variations in demographic profiles of recruited patients, dose of vitamin $\mathrm{E}$, nature of cointerventions and durations of follow-up in the included trials. It must be noted that the meta-analysis is primarily limited to the trials conducted on children, and qualitative findings of these trials correspond to the quantitative results that vitamin $\mathrm{E}$ therapy has insignificant impact on most of the clinical outcomes of patients with NAFLD. These results indicate the dire need to conduct larger trials by using fixed dose and duration of therapy among variable groups of patients so findings could be uniformly compared and standardised across the literature.

The impact of vitamin E on liver enzymes was mostly studied in adult population, while data on children are quite limited. These findings underscore the need for further studies concentrating on the histological endpoints among children. ${ }^{9}$ Vitamin E also possesses some anti-inflammatory properties. Evidence has been shown that overproduction of proinflammatory cytokines is reduced by vitamin E. ${ }^{28}$ However, high-dose vitamin E can lead to an increased risk of bleeding. ${ }^{29}$ Moreover, daily high dose of vitamin E can increase the risk of prostate cancer. ${ }^{30}$ Unfortunately, these trials did not study any safety profile of vitamin E. There is a dire need to investigate the risks of vitamin $\mathrm{E}$ therapy in both children and adults to establish safety profile.

\section{LIMITATIONS}

There was a lack of justification in outcomes of some included studies. Most of the studies were conducted on specific age groups, either adults or children. The methodological quality and sample size of studies were limited. Based on the JSC, four
Main messages

Adjuvant vitamin E therapy provides significant biochemical and histological improvements in adult patients with nonalcoholic fatty liver disease (NAFLD).

- The effect of vitamin $\mathrm{E}$ therapy on liver functioning was not significant among the paediatric population.

- The findings of the current review are limited by the short duration of trials and scarcity of safety and efficacy data of proposed treatments.

- The proven interventions in children with NAFLD are lifestyle interventions, including dietary modifications and physical exercise, that result in significant improvements in hepatic functioning.

\section{Key references}

1. Harrison SA, Torgerson S, Hayashi P, et al. Vitamin E and vitamin treatment improves fibrosis in patients with nonalcoholic steatohepatitis. Am J Gastroenterol 2003;98:2485-90.

2. Nobili V, Manco M, Devito $R$, et al. Effect of vitamin $E$ on aminotransferase levels and insulin resistance in children with non-alcoholic fatty liver disease. Aliment Pharmacol Ther 2006;24:1553-61.

3. Hoofnagle JH, Van Natta ML, Kleiner DE, et al. Vitamin E and changes in serum alanine aminotransferase levels in patients with non-alcoholic steatohepatitis. Aliment Pharmacol Ther 2013;38:134-43.

4. Sato $\mathrm{K}$, Gosho M, Yamamoto $\mathrm{T}$, et al. Vitamin $\mathrm{E}$ has a beneficial effect on nonalcoholic fatty liver disease: a meta-analysis of randomized controlled trials. Nutrition 2015;31:923-30.

\section{Current research questions}

- Does vitamin E therapy improve outcomes among patients with non-alcoholic fatty liver disease?

- On which outcomes did vitamin E show marked improvement?

- Is the impact of vitamin E equally distributed in all age groups?

- Is adjuvant vitamin E safe for adult and paediatric population?

out of nine studies were evaluated as low quality. ${ }^{11}$ Vitamin E formulation and dosage variations among studies led to difficulty in investigating the effects of different dosage regimens. Subject to these variations, pool analysis of data was not favouring the qualitative findings of the trials.

Despite mentioned limitations, all studies were RCTs, so reliable inferences improved internal causality. The current review included trials of both children and adults, hence providing detailed insight into the benefits of therapy in both age groups. Since all participants were proven histological patients with NAFLD, misclassification bias is minimised. Last but not least, the current review examined all possible outcomes related to NAFLD and the impact of vitamin E on them. 


\section{Self assessment questions}

1. What factor(s) associates with the progression of nonalcoholic fatty liver disease (NAFLD)?
A. Obesity.
B. Insulin resistance.
C. Hypertension.
D. Dyslipidaemia.
E. All of them.

2. The oxidative stress in NAFLD is primarily associated with

A. Vitamin E.

B. Reactive oxygen species (ROS).

C. Glutathione.

D. Both $A$ and $C$.

3. The primary lifestyle modification with vitamin $\mathrm{E}$ therapy which reduces disease progression in NAFLD is
A. Low protein diet.
B. Reducing weight.
C. High protein diet.
D. Both $A$ and $C$.

4. The impact of vitamin $E$ therapy on liver functioning is not remarkable in which group of patients?
A. Children.
B. Adults.
C. Elderly.
D. Women.

5. The primary role of vitamin $E$ during the management of NAFLD is

A. Oxidant potential.

B. Antioxidant activity.

C. Anti-ROS activity.

D. Both B and C.

\section{CONCLUSION}

The findings from the current review suggest that adjuvant vitamin E therapy provides significant biochemical and histological improvements in adult patients with NAFLD. The association of vitamin E therapy with normalisation of serum biochemical parameters and improved hepatic histology was not significantly observed in children. Moreover, the short duration of trials also limits the conclusion on the safety and efficacy of proposed treatments. This qualitative and quantitative review might help to revise the practice guidelines on the management of NAFLD by supplying high level of evidence.

\section{FUTURE RECOMMENDATIONS}

This review underscores the need for carefully controlled RCTs with longer duration and adequate power, particularly in children. Moreover, prospective trials must consider the appropriateness of dosage regimen so that future guidelines could be developed based on their findings.

Correction notice This paper has been corrected since it appeared Online First. Footnote $\ddagger$ has been removed from table 5 .

\footnotetext{
Acknowledgements We greatly acknowledge the support of the Statistical Department of GC University Faisalabad for providing assistance during analysis.

Contributors YHK conceptualised the plan for the current study. IAm, IAn and AG did the literature search, screening and data extraction, and drafted the manuscript. AAR performed the meta-analysis for the included studies. YHK assisted in interpreting the results. YHK and THM assessed the data quality and approved the final version of the manuscript for submission. All authors have critically reviewed the manuscript. YHK is the guarantor.
}

Funding The authors have not declared a specific grant for this research from any funding agency in the public, commercial or not-for-profit sectors.

Competing interests None declared.

Patient consent for publication Not required.

Provenance and peer review Not commissioned; externally peer reviewed.

\section{ORCID iD}

Yusra Habib Khan http://orcid.org/0000-0002-9479-6147

\section{REFERENCES}

1 Aller R, Izaola O, Gómez S, et al. Effect of silymarin plus vitamin E in patients with non-alcoholic fatty liver disease. A randomized clinical pilot study. Eur Rev Med Pharmacol Sci 2015;19:3118-24.

2 Non-Alcoholic fatty liver disease: assessment and management, NCBI, NICE guideline, no. 49. National guideline centre (UK), 2016. Available: https://www.ncbi.nlm.nih.gov/ books/NBK384738 [Accessed 12 May 2015].

3 Non-Alcoholic fatty liver disease (NAFLD), NHS choices. Available: https://www.nhs. uk/conditions/non-alcoholic-fatty-liver-disease [Accessed 12 May 2015].

4 Macaluso FS, Maida M, Petta S. Genetic background in nonalcoholic fatty liver disease: a comprehensive review. World J Gastroenterol 2015;21.

5 Arendt BM, Allard JP. Effect of atorvastatin, vitamin E and C on nonalcoholic fatty liver disease: is the combination required?. American Journal of Gastroenterology 2011;106:78-80.

6 Lavine JE, Schwimmer JB, Van Natta ML, et al. Effect of vitamin E or metformin for treatment of nonalcoholic fatty liver disease in children and adolescents: the tonic randomized controlled trial. JAMA 2011;305:1659-68.

7 Hickman I, Macdonald G. Is vitamin E beneficial in chronic liver disease? Hepatology 2007:46:288-90.

8 Pietu F, Guillaud O, Walter T, et al. Ursodeoxycholic acid with vitamin E in patients with nonalcoholic steatohepatitis: Iong-term results. Clin Res Hepatol Gastroenterol 2012;36:146-55

9 Sarkhy A, Nobili V, Al-Hussaini A. Does vitamin E improve the outcomes of pediatric nonalcoholic fatty liver disease? A systematic review and meta-analysis. Saudi J Gastroenterol 2014;20.

10 Sato K, Gosho M, Yamamoto T, et al. Vitamin E has a beneficial effect on nonalcoholic fatty liver disease: a meta-analysis of randomized controlled trials. Nutrition 2015:31:923-30.

11 Halpern SH, Douglas MJ. Appendix: Jadad scale for reporting randomized controlled trials. In: Evidence-based Obstetric Anesthesia. Oxford, UK: Blackwell Publishing Ltd, 2005: 237-8.

12 Harrison SA, Torgerson S, Hayashi P, et al. Vitamin E and vitamin C treatment improves fibrosis in patients with nonalcoholic steatohepatitis. Am J Gastroenterol 2003;98:2485-90.

13 Foster T, Budoff MJ, Saab S, et al. Atorvastatin and antioxidants for the treatment of nonalcoholic fatty liver disease: the ST Francis heart study randomized clinical trial. Am J Gastroentero/ 2011:106:71-7.

14 Hoofnagle JH, Van Natta ML, Kleiner DE, et al. Non-alcoholic steatohepatitis clinical research network (NASH CRN). (2013). vitamin E and changes in serum alanine aminotransferase levels in patients with non-alcoholic steatohepatitis. Aliment Pharmacol Ther; $38: 134-43$.

15 Sanyal AJ, Chalasani N, Kowdley KV, et al. Pioglitazone, vitamin E, or placebo for nonalcoholic steatohepatitis. N Eng/ J Med 2010;362:1675-85.

16 Nobili V, Manco M, Devito R, et al. Effect of vitamin E on aminotransferase levels and insulin resistance in children with non-alcoholic fatty liver disease. Aliment Pharmacol Ther 2006:24:1553-61.

17 Nobili V, Manco M, Devito R, et al. Lifestyle intervention and antioxidant therapy in children with nonalcoholic fatty liver disease: a randomized, controlled trial. Hepatology 2008;48:119-28.

18 Vajro P, Mandato C, Franzese A, et al. Vitamin E treatment in pediatric obesity-related liver disease: a randomized study. J Pediatr Gastroenterol Nutr 2004;38:48-55.

19 Hamaguchi M, Kojima T, Takeda N, et al. The metabolic syndrome as a predictor of nonalcoholic fatty liver disease. Ann Intern Med 2005;143:722-8.

20 Bacon BR, Farahvash MJ, Janney CG, et al. Nonalcoholic steatohepatitis: an expanded clinical entity. Gastroenterology 1994;107:1103-9.

21 Kim GH, Chung JW, Lee JH, et al. Effect of vitamin E in nonalcoholic fatty liver disease with metabolic syndrome: a propensity score-matched cohort study. Clin Mol Hepatol 2015;21:379.

22 Parola M, Muraca R, Dianzani I, et al. Vitamin E dietary supplementation inhibits transforming growth factor beta 1 gene expression in the rat liver. FEBS Lett 1992;308:267-70

23 Wittlin L, Logomarsino JV. Therapeutic effects of vitamin E supplementation in liver diseases and transplantation. J Gastroenterol Hepatol Res 2014:3:1095-102.

$24 \mathrm{Li} \mathrm{J}$, Cordero P, Nguyen V, et al. The role of vitamins in the pathogenesis of nonalcoholic fatty liver disease. Integr Med Insights 2016;11:IMI-S31451. 
25 Erhardt A, Stahl W, Sies H, et al. Plasma levels of vitamin E and carotenoids are decreased in patients with nonalcoholic steatohepatitis (NASH). Eur J Med Res 2011;16:76.

$26 \mathrm{Xu} \mathrm{R}$, Tao A, Zhang S, et al. Association between vitamin $\mathrm{E}$ and non-alcoholic steatohepatitis: a meta-analysis. Int J Clin Exp Med 2015;8:3924.

27 Zöhrer E, Alisi A, Jahnel J, et al. Efficacy of docosahexaenoic acid-choline-vitamin E in paediatric NASH: a randomized controlled clinical trial. Appl Physiol Nutr Metab 2017:42:948-54.

28 Singh U, Devaraj S, Jialal I. Vitamin E, oxidative stress, and inflammation. Annu Rev Nutr 2005;25:151-74.

29 Wittlin L, Logomarsino J. V. Therapeutic effects of vitamin E supplementation in liver diseases and transplantation. J Gastroenterol Hepatol Res 2014;3:1095-102.
30 Klein EA, Thompson IM, Tangen CM, et al. Vitamin $\mathrm{E}$ and the risk of prostate cancer: the selenium and vitamin $\mathrm{E}$ cancer prevention trial (select). JAMA 2011;306:1549-56.

Answers

1. E. All of them.

2. B. Reactive oxygen species.

3. B. Reducing weight.

4. A. Children.

5. D. Both B and C. 